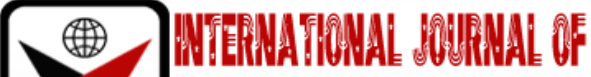

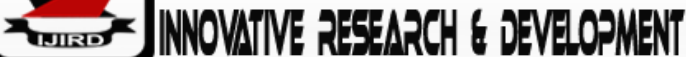

ISSN 2278 - 0211 (Online)

\section{The Hazards of Radiation of Telecommunication Mast on Male Rabbits Reproductive Parameters}

\begin{tabular}{c} 
Akintunde, $\mathbf{0 . W .}$ \\
Senior Lecturer, Department of Anatomy, \\
Kadoke Akintola University of Technology, Ogbomoso, Nigeria \\
Kolawole, Z.B. \\
Technologist, Department of Anatomy, \\
Ladoke Akintola University of Technology, Ogbomoso, Nigeria \\
Abdulrahman, A. \\
Lecturer, Department of Anatomy, \\
Ladoke Akintola University of Technology, Ogbomoso, Nigeria \\
Joseph, 0.0. \\
Laboratory Instructor, Department of Anatomy, \\
Ladoke Akintola University of Technology, Ogbomoso, Nigeria \\
\hline
\end{tabular}

\section{Abstract:}

Background:There has been growing public concern on the effects of electromagnetic radiation (EMR) attributed to new technologies such as telecommunication which produced radiation for cellular phones on human health. Many studies have recently been published on this topic. However, possible consequences of the cellular phone usage on human reproductive parameters have not been investigated adequately.

Aim of the work: This work was carried out to evaluate the effects of telecommunication mast (TM) radiation exposure on some reproductive parameters of male rabbits.

Materials and methods: Twenty-five (25) male rabbits with an average weight of $600 \mathrm{~g}-1,270 \mathrm{~g}$ were divided into 5 groups, (n=5), with consideration towards size variation. Group $E$ was served as the control while groups $A, B, C$ and $D$ were the treated groups placed at a distance measured in feet $(f t)(0,5,10$, and $15 f t)$ around a telecommunication mast (TM). Group A ( $0 \mathrm{ft}$ ) was directly under the mast and Group D (15ft away) was the farthest from the mast while the group $E$ (Control) was kept away from the vicinity of the mast.

On the last day of 54th day of exposure to the mast tower, the rabbits were weighed and thereafter slaughtered by the use of chloroform as a sedative. The testes were removed for histomorphometric and histologic studies (using Hematoxylin and Eosin staining techniques) and semen was also collected from their epididymides for sperm examination.

Results: Degenerative changes were observed in testes in the form of testicular atrophy which is primarily associated with shrinkage of the seminiferous tubules and loss of sperm cells and widening of the interstitial space with a mild shrinkage of the interstitial cells. A significant decline in the number of sperm cell count of the most exposed groups and a significant increase in the number of dead cell and non-motile cell. Moreover, histomorphometric analysis of the seminiferous was investigated and a significant reduced value of the seminiferous cross sectional area (CSA) was observed. Meanwhile, the mean value for the seminiferous luminal diameter (LD) in the most exposed group was significantly increased and value of the seminiferous epithelia height (GEH) in the most exposed and the adjacent groups were significantly increased. Where as seminiferous tubule diameters (STD) of the exposed rabbits in all the groups were insignificantly decreased. Therefore, the result is distance-dependent from the most distanced group down to nearest group to the mast.

Conclusions: The results of this study showed that long-term exposure of radiation from telecommunication mast resulted in damage to male rabbit reproductive parameters, therefore establishes that there are reproductive health implications of exposure to mast radiation and minimizing this exposure will go a long way to improve healthy living.

Keywords: Rabbit, telecommunication mast, testes, reproductive

\section{Introduction}

Network mast also known as cell phone base stations may be free-standing towers or mounted on existing structures such as water tank or tall buildings. Cell phones communicate with near-by cell towers mainly through 
radiofrequency (RF) waves, a form of energy in the electromagnetic spectrum between FM radio waves and microwaves. Waves like FM radio waves, microwaves and heat are forms of non-ionizing radiation (American Cancer Society, 2018).

When a person makes phone call, a signal is sent from the phone's antenna to the nearest base station antenna. The base station responds to this signal by signing it an available radiofrequency (RF) channel. RF transfers the voice information to the base station. The voice signals are then sent to a switching center, which transfers the call to its destination. Voice signals are then relayed back and during the call.Absorption of radiofrequency radiation (RFR) depends on many factors including the transmission frequency and the power density. Other factors include the size, shape, mineral and water content of the organism. Children absorb energy differently than adults because of the differences in anatomies and tissue composition (American Cancer Society, 2018).From the early genesis of cell phone technology in the early 1980s, cell towers were presumed safe when located near populated areas because they are low-power installations in comparison with broadcast towers. This thinking already depended on the assumption that broadcast towers were safe if kept below certain limits. Therefore, the reasoning went, cell towers would be safer still. The thinking also assumed that exposures between cell and broadcast towers were comparable. In certain cities, cell and broadcast tower transmissions both contributed significantly to the ambient levels of RFR (Sirav and Seyhan 2019; Joseph et al. 2010). There are several fallacies in this thinking, including the fact that broadcast exposures have been found unsafe even at regulated thresholds (Park et al. 2002).

There was an association between field strength and cardiovascular symptoms and associations between radiation, headache, nausea, loss of appetite, unwellness, sleep disturbance, depression, lack of concentration and dizziness (Altpeter et al. 2000). The human body physically absorbs microwaves, this leads to rotation of dipole molecules and to inversion transitions, causing a warming effect. The fact that the human body transmits microwave radiation at a very low intensity means that since every transmitter represents a receiver and transmitter at the same time, we know the human body also acts as a receiver (SCENIHR 2009, ICNIRP 1998).

The concerns about the radiation from mast have induced a large body of research (both epidemiological and experimental, in non-humans animals as well as in humans (Fews, et al., 1999) likewise other digital wireless systems, power lines and towers. There are publications which supports the existence of complex biological effects of weaker nonthermal EMF (SAGE Report, 2011; Maslanyi, et al., 2010, Huss et al., 2009; Binhi, et al., 2002). Very strong radiation can induce current capable of delivering an electrical shock to persons and animals. It can also overload and destroy electrical equipment (IEEE Standard, 2005; Aalto et al., 2006). Although several literatures confirm that radiation at high levels over a period of time affect people living around radiation sources such as cell towers, transmission power lines and so on (Ahlbom, et al., 2001).Children absorb energy differently than adults because of differences in their anatomies and tissue composition. Children are not just "little adults". For this reason, and because their bodies are still developing, children may be more susceptible to damage from cell phone radiation. For instance, radiation from a cell phone penetrates deeper into the head of children (Gandhi et al. 1996; Wiart et al. 2008) and certain tissues of a child's head, e.g., the bone marrow and the eye, absorb significantly more energy than those in an adult head (Christ et al. 2010).

The transmitter is placed directly against the head during cell phone use whereas proximity to a cell tower will be an ambient exposure at a distance. There is little difference between cell phones and the domestic cordless phones used today. Both use similar frequencies and involve a transmitter placed against the head. But the newer digitally enhanced cordless technology (DECT) cordless domestic phones transmit a constant signal even when the phone is not in use, unlike the older domestic cordless phones. But some DECT brands are available that stop transmission if the mobile units are placed in their docking station.

\section{Materials and Methods}

The material used for the experiment was Telecommunication mast (tower) which is essential to produce the radiation needed. Other materials include cages made of wood, wire gauze and net. The floor of the cages was made of wood to make it comfortable for the rabbits, and it was covered with sawdust to provide a soft floor for the rabbits and to make cleaning of the cage convenient when littered. The male rabbits were purchased from the department of Animal Production and Health sciences, Faculty of Agricultural sciences, LadokeAkintola University of technology, Ogbomoso.

\subsection{Experimental Design and Animal Grouping}

Twenty-five (25) male rabbits with an average weight of $600 \mathrm{~g}-1,270 \mathrm{~g}$ were divided into 5 groups, (n=5), with consideration towards size variation. They were fed with rabbit's pellets, and water was given ad libitum. The rabbits were left to acclimatize for two(2) weeks before the study commenced. Group E was served as the control while groups A, B, C and $\mathrm{D}$ were the treated groups placed at a distance measured in feet $(\mathrm{ft})(0,5,10$, and $15 \mathrm{ft})$ away from each other around a telecommunication mast. Group A (0ft) was directly under themast and Group D (15ft away) was the farthest from the mast while the group E (Control) was kept away from the vicinity of the mast. The experiment lasted 54 days before the rabbits were sacrificed.

\subsection{Animal Slaughter and Sample Collection}

On the last dayof the experiment, the rabbits were weighed and thereafter slaughtered by the use of chloroform as a sedative. Their abdominal cavities were cut opened by a midline abdominal incision and the reproductive organs (testes) were removed for histomorphometric and histologic studies (using Hematoxylin and Eosin staining techniques) and semen was also collected from their epididymides for sperm examination. 


\subsection{Measurement of Testicular Weight}

The left and right testes of the rats in all the groups were dissected out freed from adherent tissues, and their average weight were taken to the nearest $0.01 \mathrm{~g}$ on a Scout SE analytical scale(Ohaus Instrument,USA). The result was computed per $100 \mathrm{~g}$ of the body weight.

\subsection{Histological Study}

After sacrifice, the gonads are collected, degreased and fixed in Holland Bouin'sfluid for 10 days and dehydrated in ethanol bath at increasing degrees $\left(50^{\circ}, 70^{\circ}, 80^{\circ}, 90^{\circ}, 100^{\circ} \mathrm{C}\right)$ and then included in paraffin wax by means of a moving and coating device (Leica type). Samples were cut into serial histological sections of $5 \mathrm{~mm}$ thickness with Leica Microsystem microtome at the Laboratory. Topographical coloring used were Masson's trichrome (Goldner variant) and hematoxylineosin (Martoja, et al., 1967)). The observation of histological sections was performed by OPTIKA microscope at different magnifications.

\subsection{Histomorphometric (Stereological) Evaluation of the Testes}

A morphometric study was carried out on testicular structures of rabbits of $600 \mathrm{~g}-1,270 \mathrm{~g}$ in order to determine the Cross Sectional Area (CSA) of the seminiferous tubules, diameter of the seminiferous tubule (DST), Luminal Diameter (LD) and Germinal Epithelial Height (GEH) using 'Imagej®' (an open source image processing software, designed for scientific multidimensional images). Histomorphometric data was collectedwith the aid of a Leica (DM 750) digital microscope (Leica Microsystems, Switzerland).

\subsection{Statistical Analysis}

Quantitative data on histomorphometric analysis, sperm parameters and organ weight was presented in form of tables and expressed as mean \pm SEM with $p$-value of $(p \leq 0.05)$. The treated groups were statistically compared to control group with column statistics using Graph Pad Prism version 5.01 inc. U.S.A.

\section{Results}

\subsection{Changes in organs weight}

The effects on organ average weight with telecommunication mast radiation exposed groups showed a distancedependent reduction in average weight. There was statistically significant $(\mathrm{P} \leq 0.05)$, decrease in testicles average weight $0.66 \pm 0.24$ and $1.28 \pm 0.84$ in distance of 0 feetand 5 feet away from the mast. There was also a distance-dependent statistical non -significant decrease $(P>0.05), 1.39 \pm 0.68$ and $1.68 \pm 0.05$ on the testiclesaverage weight on groups with distances of 10 feet and 15 feet away from the tower when compared with control group (Table 1).

\begin{tabular}{|c|c|c|c|c|c|}
\hline Group & A & B & C & D & E(Control) \\
\hline Weight $(\mathrm{g})$ & $0.66 \pm 0.24$ & $1.28 \pm 0.84$ & $1.39 \pm 0.68$ & $1.68 \pm 0.05$ & $1.89 \pm 0.06$ \\
& $* 0.02$ & $* 0.05$ & $* * 0.92$ & $* * 0.66$ & \\
\hline
\end{tabular}

Table 1: Comparison of Testicular Average Weight (G) of Control and Experimental Rats

\subsection{Sperm Count Analysis}

Sperm quantity evaluation revealed distance-dependent decrease in the percentage count of the sperm cells.From the result on table 2, the control group $\mathrm{E}$, had the highest number of spermatozoa $(50.13 \pm 9.13) \times 10^{6} / \mathrm{mL}$, while the treated groups had the lowest percentage value at group A ( $0 \mathrm{ft})(28.00 \pm 0.81) \times 10^{6} / \mathrm{mL}$ followed by group B (5ft away) ( $30.50 \pm 1.67) \times 10^{6} / \mathrm{mL}$, group C (10ft away) $(34.50 \pm 3.64) \times 10^{6} / \mathrm{mL}$ and group $\mathrm{D}$ with distance of $15 \mathrm{ft}(34.93$ $\pm 3.19) \times 10^{6} / \mathrm{mL}$.

\begin{tabular}{|c|c|c|c|c|c|}
\hline Group & A & B & C & D & E(Control) \\
\hline Count $\times 10^{6} / \mathrm{ml}$ & $\begin{array}{c}28.00 \pm 0.81 \\
* 0.02\end{array}$ & $\begin{array}{c}30.50 \pm 1.67 \\
* * 0.07\end{array}$ & $\begin{array}{c}34.50 \pm 3.64 \\
* * 0.27\end{array}$ & $\begin{array}{c}34.93 \pm 3.19 \\
* * 0.22\end{array}$ & $50.13 \pm 9.13$ \\
\end{tabular}

Table 2: The Distribution of Mean and Standard Error of Mean (SEM) for the Sperm Count Analysis

*Indicates the P Value Is Significant at $<0.05$, Otherwise **Indicates P Value Is Not Significant at $>0.05$

\subsection{Motility Grading}

Table 3 showed that the percentage motile spermatozoa of the rapid progressive motile spermatozoa (RPM) vary from $60.00 \pm 5.77 \%$ to $15.00 \pm 2.89 \%$ with a highly significant difference $(\mathrm{p}<0.02)$ of group A $(15.00 \pm 2.89 \%)$.

A percentage of Slow Progressive Motility (SPM) of $20.00 \pm 0.58 \%$ was observed at group A and $15.00 \pm 3.383 \%$ at group E. These variations in SPM were highly significant $(\mathrm{p}<0.05)$ at group A and group B (respective percentage SPM of $20.00 \pm 0.58 \%$ and $18.05 \pm 0.58 \%$ ) and insignificant at group C and group D (respective percentage SPM $16.75 \pm 0.58 \%$ and $15.90 \pm 2.89 \%)$.

The evolution of the non-progressive motility (NPM) in table 3 showed a progressive increase in NPM with a highly significant $(\mathrm{p}<0.05)$ increase in rabbits between group A and group B (with the respective values of $26.66 \pm 2.89 \%$ and $23.00 \pm 5.77 \%$ and insignificant at group $\mathrm{C}$ and group $\mathrm{D}$ (with the respective values of $16.67 \pm 3.38 \%$ and 14.20 $\pm 2.89 \%)$. 
Meanwhile, the evolution of the Dead Sperm Cells (DSC) of the testes (table3) is progressively increase significantly between the exposed groups with highly significant at groups A, B and C $(40.00 \pm 0.57 \%, 36.33 \pm 12.02 \%$ and $40.00 \pm 0.58 \%$ respectively, and less significant at group D (30.00 $\pm 11.55 \%)$.

\begin{tabular}{|c|c|c|c|c|c|}
\hline Groups & A & B & C & D & E(Control) \\
\hline RPM (\%) & $15.00 \pm 2.89$ & $22.00 \pm 0.58$ & $26.67 \pm 16.68$ & $40.00 \pm 17.32$ & $60.00 \pm 5.77$ \\
& $* 0.02$ & $* 0.04$ & $* * 0.21$ & $* * 0.20$ & \\
\hline SPM (\%) & $20.00 \pm 0.58$ & $18.05 \pm 0.58$ & $16.75 \pm 0.58$ & $15.90 \pm 2.89$ & $15.00 \pm 3.383$ \\
& $* 0.04$ & $* * 0.05$ & $* * 0.06$ & $* * 0.84$ & \\
\hline NPM (\%) & $26.66 \pm 2.89$ & $23.00 \pm 5.77$ & $16.67 \pm 3.38$ & $14.20 \pm 2.89$ & $13.33 \pm 3.38$ \\
& $* 0.04$ & $* 0.05$ & $* * 1.00$ & $* * 0.84$ & \\
\hline DSC (\%) & $40.00 \pm 0.57$ & $36.33 \pm 12.02$ & $40.00 \pm 0.58$ & $30.00 \pm 11.55$ & $11.00 \pm 0.58$ \\
& $* 0.01$ & $* 0.03$ & $* 0.02$ & $* 0.05$ & \\
\hline
\end{tabular}

Table 3: The Distribution of Mean and Standard Error of Mean (SEM) for the Sperm Motility Grading

*Indicates the P Value Is Significant at $<0.05$, Otherwise **Indicates $P$ Value Is Not Significant at $>0.05$ RPM=Rapid Progressive Motility, SPM = Slow Progressive Motility,

NPM = Non Progressive Motility And DSP = Dead Sperm Cells

\subsection{Morphological Grading}

Morphologically, the percentage of normal sperm cells was observed in table 4 with the control group $\mathrm{E}$ had the highest percentage of sperm cell number $(61.65 \pm 0.57 \%)$ when compared with the exposed groups, the group A which was directly under the tower had significant $(\mathrm{P}<0.05)$ reduction of number of normal sperm cells $(23.33 \pm 2.89 \%)$ followed by an insignificant $(\mathrm{P}>0.05)$ number of normal sperm cell of group B $(30.00 \pm 0.57 \%)$, Group C $(35.00 \pm 2.88 \%)$ and group D $(38.00 \pm 0.57 \%)$.

The deformities to the sperm structures vary from head to tail deformities of the exposed rabbits testes, group A animals recorded a highest number of insignificant $(\mathrm{P}>0.05)$ morphological defect, its head defect cell percentage was $50.00 \pm 0.58 \%$ and tail defect cell was $15.00 \pm 0.57 \%$ followed by group B with head defect of $47.00 \pm 0.57 \%$ and tail defect of 13.00 \pm 1.16 . Group C percentage of cells that had head deformed structure was $41.33 \pm 3.38 \%$ and its tail deformed was $10.00 \pm 0.57$ and group D rabbits had $40.00 \pm 2.89 \%$ of head defected cells and $10.00 \pm 0.57 \%$ of tail defected cells.

Meanwhile, the control group $\mathrm{E}$ had the lowest number of morphological defected spermatozoa which was $12.00 \pm 0.58 \%$ head defect and $10.02 \pm 1.16 \%$ tail defect spermatogenic cells (Table 4 ).

\begin{tabular}{|c|c|c|c|c|c|}
\hline Group & A & B & C & D & E(Control) \\
\hline Normal Sperm & $23.33 \pm 2.89$ & $30.00 \pm 0.57$ & $35.00 \pm 2.88$ & $38.00 \pm 0.57$ & $61.65 \pm 0.57$ \\
Cell (\%) & $* 0.04$ & $* * 0.06$ & ${ }^{* *} 1.00$ & ${ }^{* *} 1.00$ & \\
\hline HeadDefect (\%) & $50.00 \pm 0.58$ & $47.00 \pm 0.57$ & $41.33 \pm 3.38$ & $40.00 \pm 2.89$ & $12.00 \pm 0.58$ \\
& $* * 0.06$ & ${ }^{* *} 0.08$ & $* * 1.00$ & $* 1.00$ & \\
\hline Mid-Piece Defect & $11.66 \pm 1.16$ & $10.00 \pm 1.15$ & $13.67 \pm 3.38$ & $12.00 \pm 0.58$ & $14.36 \pm 0.58$ \\
(\%) & $* * 0.40$ & $* * 0.06$ & $* * 1.00$ & ${ }^{* *} 1.00$ & \\
\hline Tail Defect (\%) & $15.00 \pm 0.57$ & $13.00 \pm 1.16$ & $10.00 \pm 0.58$ & $10.00 \pm 0.57$ & $10.02 \pm 1.16$ \\
& $* * 0.40$ & $* * 1.00$ & ${ }^{* * 1.00}$ & ${ }^{* *} 1.00$ & \\
\hline
\end{tabular}

Table 4: The Distribution of Mean and Standard Error of Mean (SEM) for the Sperm Morphological Grading *Indicates the P Value Is Significant at $<0.05$, Otherwise ${ }^{* *}$ Indicates P Value Is Not Significant at $>0.05$

\subsection{Histomorphometric Analysis}

The mean seminiferous cross sectional area(CSA) within the experimental animals in all the groups was significantly different $(\mathrm{P}<0.05)$. From Table 5 , it was found that group A ( $0 \mathrm{ft})$ had the lowest mean value $(22.91 \pm 1.05 \mu \mathrm{m})$, followed by group B ( $5 \mathrm{ft}$ away) $(23.20 \pm 0.44 \mu \mathrm{m})$, while the group with the highest value was group D (15feet away) $(31.92 \pm 1.35 \mu \mathrm{m})$.

There were markedly significant statistical differences in seminiferous luminal diameter (LD) in the experimental animal testes in all the groups. The mean $( \pm$ SEM) for the seminiferous luminal diameter in group A and B (1foot and 5 feet away) $(4.10 \pm 0.21 \mu \mathrm{m}$ and $4.24 \pm 0.79 \mu \mathrm{m})$ had significant increase values $(\mathrm{P} \leq 0.05)$, followed by groups $\mathrm{C}$ and $\mathrm{D}(10 \mathrm{ft}$ and $15 \mathrm{ft}$ away) (3.64 $\pm 0.35 \mu \mathrm{m}$ and $3.47 \pm 0.55 \mu \mathrm{m})$ with insignificant increase value $(\mathrm{P}>0.05)$; while group $\mathrm{E}$, control had the least mean value $(2.62 \pm 0.15 \mu \mathrm{m})$ (Table 5$)$.

There were statistical differences in the seminiferous germinal epithelia height (GEH) of the experimental animals in all the groups. The mean value $( \pm S E M)$ for the seminiferous epithelia height in groups A and B $(0.97 \pm 0.06 \mu \mathrm{m}$ and 0.97 $\pm 0.09 \mu \mathrm{m})$ were significantly increased $(\mathrm{P} \leq 0.05)$, followed by insignificant increase $(\mathrm{P}>0.05)$ values of groups Cand $\mathrm{D}$ $(1.08 \pm 0.34 \mu \mathrm{m}$ and $1.11 \pm 0.12 \mu \mathrm{m})$ when compared with the control group E $(1.93 \pm 0.87 \mu \mathrm{m})$ (Table 5).

Lastly, the diameter of seminiferous tubule(DST) of the experimental animals in all the groups were insignificantly decreased $(\mathrm{P}>0.05)$ when compared with the control group $(7.95 \pm 1.72 \mu \mathrm{m})$. The table 5shows that the mean $( \pm$ SEM) for DST, the result is distance-dependent manner from group D $(6.673 \pm 1.05 \mu \mathrm{m})$ to group A $(5.70 \pm 0.15 \mu \mathrm{m})$ (Table 5). 


\begin{tabular}{|c|c|c|c|c|c|}
\hline Group & A & B & C & D & E (Control) \\
\hline CSA $(\mu \mathrm{m})$ & $22.91 \pm 1.05$ & $23.20 \pm 0.44$ & $25.79 \pm 1.16$ & $31.92 \pm 1.35$ & $39.34 \pm 3.63$ \\
& $0.01^{*}$ & $0.02^{*}$ & 0.139 & 0.81 & \\
\hline DST $(\mu \mathrm{m})$ & $5.70 \pm 0.15$ & $5.977 \pm 0.1785$ & $6.06 \pm 0.99$ & $6.673 \pm 1.05$ & $7.95 \pm 1.72$ \\
& 0.79 & 0.3949 & 0.94 & 0.69 & \\
\hline GEH $(\mu \mathrm{m})$ & $0.97 \pm 0.06$ & $0.97 \pm 0.09$ & $1.08 \pm 0.34$ & $1.11 \pm 0.12$ & $1.93 \pm 0.87$ \\
& 0.03 & 0.05 & 0.94 & 0.41 & \\
\hline LD $(\mu \mathrm{m})$ & $4.10 \pm 0.21$ & $4.24 \pm 0.79$ & $3.64 \pm 0.35$ & $3.47 \pm 0.55$ & $2.62 \pm 0.15$ \\
& $0.01^{*}$ & 0.05 & 0.12 & 0.21 & \\
\hline
\end{tabular}

Table 5: The Distribution of Mean and Standard Error of Mean (SEM) for the Seminiferous Tubule Histomorphometric Analysis in Experimental Rats' Testes Compared to the Control Rats In Micron

CSA: Cross Sectional Area, DST: Diameter of Seminiferous Tubule, LD: Luminal Diameter, GEH: Germinal Epithelium Height. Values Are Expressed as Mean \pm SEM. ${ }^{*} P<0.05$

\subsection{Histological Examination of Testes Exposed to Radiation from Phone Tower in Comparison with Control Group}

When the histological section of the control group E was compared with the groups exposed to phone tower radiation the results showed observable differences in the various aspects of the histological features. Degenerative changes were observed in testes in the form of testicular atrophy which is primarily associated with shrinkage of the seminiferous tubules and loss of sperm cells and widening of the interstitial space with a mild shrinkage of the interstitial cells.

Control group E, showed normal morphological presentation. Group A treatment relative to B treatment showed similar morphological appearance of atrophic testes with altered and distorted seminiferous tubules, proliferation and wide interstitial space with increase of interstitial Leygid's cells and thin basement membrane, however, mild widening of the interstitial space with a mild shrinkage of the interstitial cells is observed in groups C and D treatments.

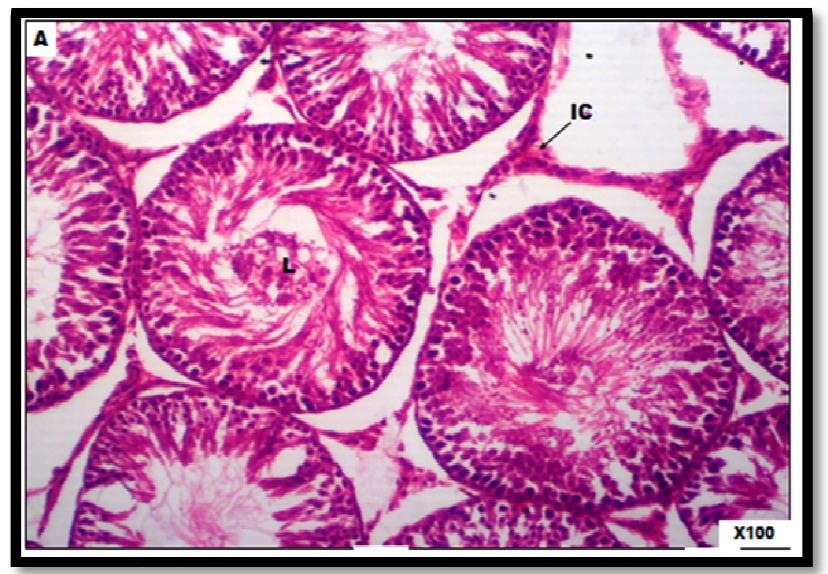

Figure 1: Photomicrograph of the Transverse Section of the Experimental Group A Testes Showingatrophic Testes with Altered and Distorted Seminiferous Tubules, Proliferation and Increase of Leygid'sCells (IC) and Thin Basement Membrane Hematoxylinand Eosin Stain (100x)

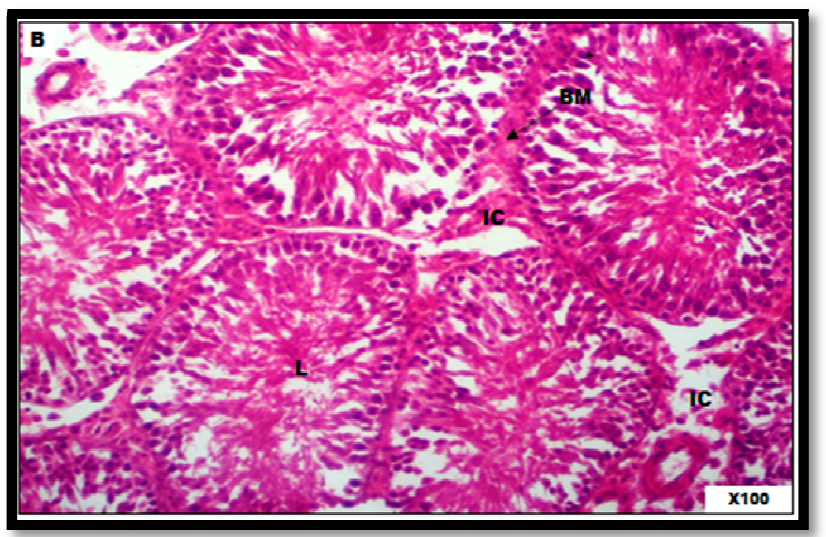

Figure 2: Photomicrograph of the Transverse Section of the Experimental Group $B$ Rats Testes Showing Distorted Seminiferous Tubules, Proliferation and Joined Basement Membrane, Hematoxylin and Eosin Stain 


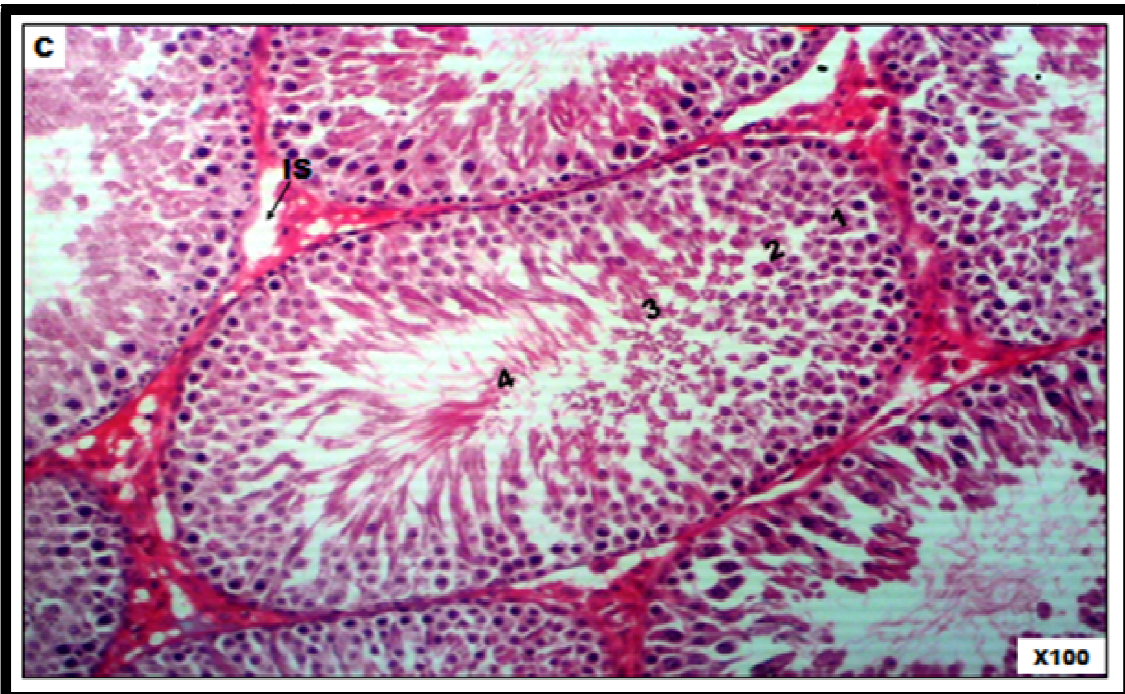

Figure 3: Photomicrograph of the Transverse Section of the Experimental Group C Rats Testes Showing Irregular Shaped Seminiferous Tubules and Regeneration of Spermatogonia Hematoxylinand Eosin Stain (100x)

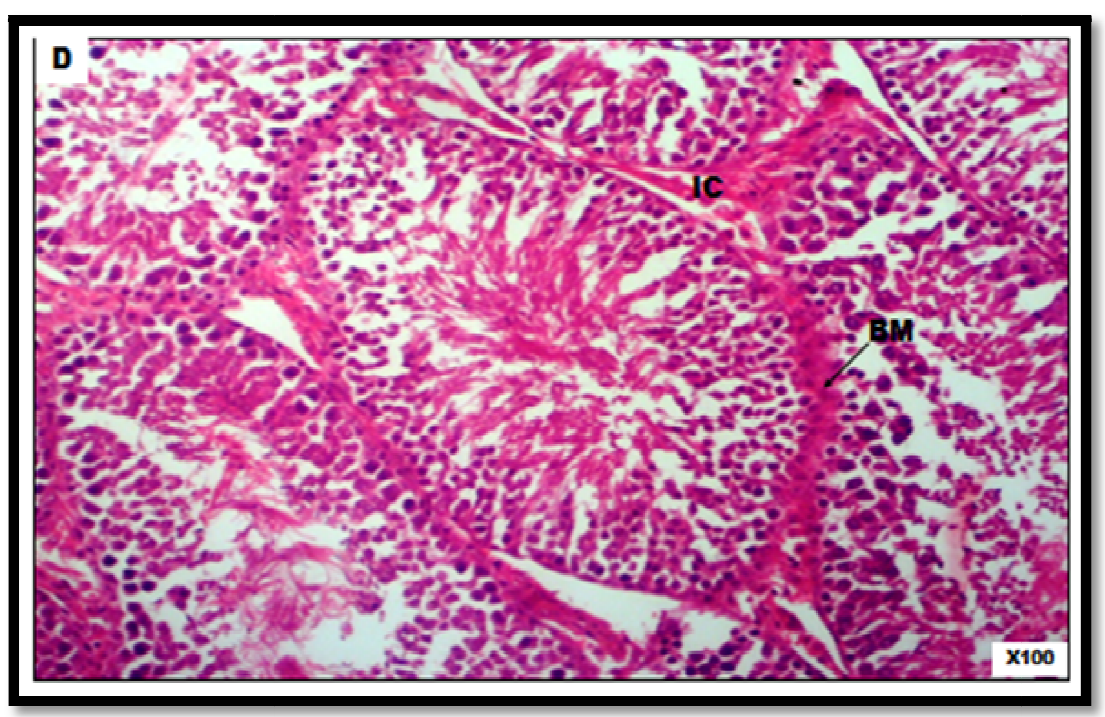

Figure 4: Photomicrograph of the Transverse Section of the Experimental Group D Testes Showing Atrophic Testes with Altered and Distorted Seminiferous Tubules, Proliferation and Increase of Interstitial Leygid'sCells (IC) and Thin Basement Membrane Hematoxylinand Eosin Stain (100x)

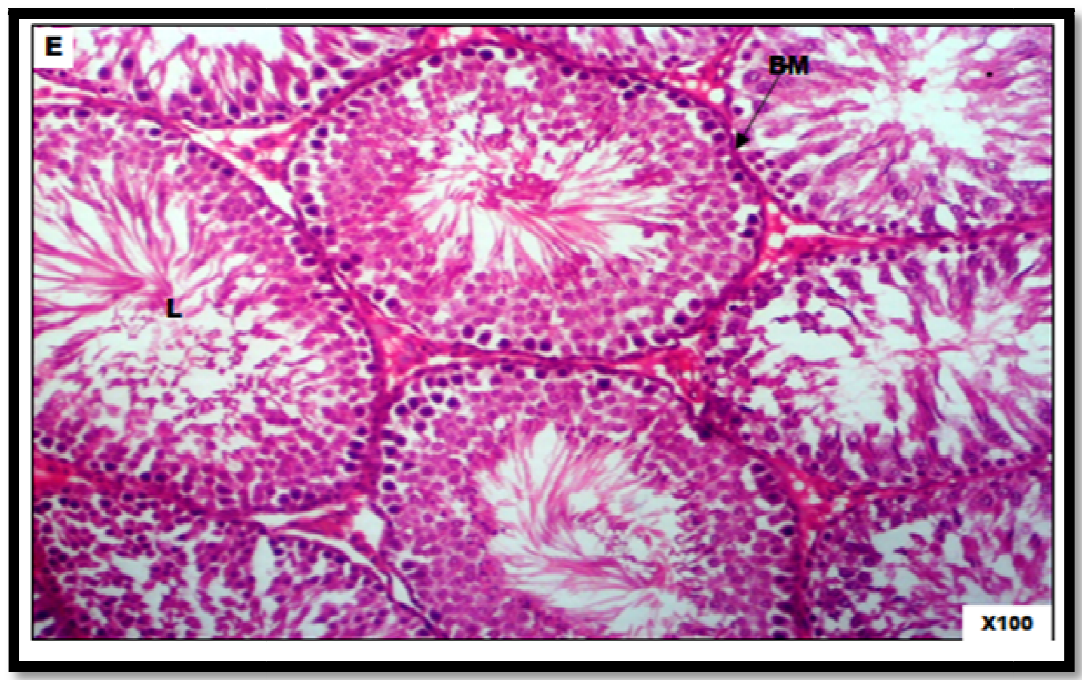

Figure 5: Photomicrograph of the Transverse Section of the Experimental Group E Testes, Showing Control Group with Normal 


\section{Discussion}

Two areas of the body; the eyes and the testes, can be particularly susceptible to heating by RF energy because of the relative lack of available blood flow to dissipate the excessive heat load. Temporary sterility, caused by such effects as changes in sperm count and in sperm motility, is possible after exposure of the testes to high-level RF radiation (SAGE report, 2011).

Testicular dysfunction, due to either endogenous or exogenous factors, may result in a decline in male sexual activeness, androgen synthesis, and fertility. In this study, adverse effect of the radiation from the phone mast on testicular dysfunction in male rabbits is reported.

We found that exposure of rabbits to telecommunication phone mast radiation leads to distance-dependent significant decrease in the testicular weight; similar changes were demonstrated in a previous study conducted on the effects of exposure to mobile phones on the testicular structure and function of adult rabbits. That study indicated that short-term exposure of mobile phone radiation leads to a statistically non-significant decrease in serum testosterone levels and testicular weight (Okechukwu, 2018).

Microscopic variables such as the appearance of elongated spermatids and spermatozoa in the semini ferous tubules, the diameter, number and size of the interstitial and germ cells have been used as indicators of maturity (Schinckel, 1983; Tegegne, 1991). These parameters are consistent with moderately macroscopic variables (Schinckel, 1983; Chemes, 2001) giving additional information about the functional maturity of the testes. In the current work, the histomorphometric analysis of the seminiferous tubules shows that the exposure of rabbits to phone mast radiation has insignificant reductive effect on the seminiferous cross sectional area, diameter and height which are evident in the size and weight of the testes.

According to the results of Ali, the chronic exposure to RF-EMR from a cell phone causes the impaired testicular function accompanied by a changing histological parameters showed a change in cross-section, luminal and bacterial epithelium diameter in all experimental groups(Ali, 2020).It was also reported that using a conventional cellular phone led to a decreased mean seminiferous tubular diameter in the testes of rats (Al-Damegh, 2012; Salama, et al; 2010).

We recorded from this study that the group placed nearest to the phonemast had the highest percentage of number of sperm cell defects, lowest percentage of number of motile sperm cell with a significant low sperm cells count when compared with the other exposed groups and the control group.These results do match to those obtained by Erogul and Salama, et al who reported that electromagnetic Radiation (EMR) exposure caused a subtle decrease in the rapid progressive and slow progressive sperm movement. It also caused an increase in the no-motility category of sperm movement (Erogul, 2006). A decrease in the diameter of the seminiferous tubules, a fall in sperm concentration, and a decline in the motile sperm population in the phone exposed group compared with the control group was also reported (Salama, et al; 2010).

The testis consists mainly of seminiferous tubules where takes place spermatogenesis and interstitial tissue rich in Leydig cells. These synthesize and release androgens, mainly testosterone which playing a role in maintenance of spermatogenesis. Magras and Xenos (1997) reported a decrease in reproductive function in mice exposed to RFR at power densities of $0.000168-0.001053 \mathrm{~mW} / \mathrm{cm} 2$. There was regeneration of spermatogonia in the seminiferous tubules of the rabbits exposed to the radiation. These findings further support the activity of the phone mast radiation exposure in this present study that caused testicular atrophy which is primarily associated with shrinkage of the seminiferous tubules and loss of sperm cells and widening of the interstitial space with a mild shrinkage of the interstitial cells.

\section{Conclusion}

The excessive exposure to telecommunication mast leads to the generation of electromagnetic radiation and subsequently caused environmental pollution. It has been observed that exposing rabbits to the telecommunication mast for almost 8 weeks or exposure to radiation generated from electromagnetic radiation stations and for the same period, this affects the testicle cells, as well as the production of sperms in groups exposed to radiation compared to protected groups, which are considered as a control group.

These kinetic data obtained from the study on rabbit testicles exposed to electromagnetic radiation of telecommunication mast can contribute to a better knowledge about the adverse effects on male reproductive parameters exposure to environmental pollution caused by the mast radiation and the control of reproductive performance and production in the society.

\section{References}

i. Aalto S., Haarala C., Bruk A., Sipila H., Hamalainen H., Rinne J.0.(2006) 'Mobile phone affects cerebral blood flow in humans' Journal of cerebral blood flow and metabolism 26(7) 885-90.

ii. Ahlbom A., Cardis E., Green A., Linet M., Savitz, Swerdlow A,(2001). 'Review of the epidemiological literature on EMF and health environs': Health Perspect 109 (Suppl 6).

iii. Al-Damegh MA. (2012) Rat testicular impairment induced by electromagnetic radiation from a conventional cellular telephone and the protective effects of the antioxidants vitamins $C$ and E. Clinics (Sao Paulo); 67:785-792.

iv. Ali BMH (2020) Study the electromagnetic radiation effects on testicular function of male rats by biochemical and histopathological. Eurasia J Biosci 14: 3869-3873.

v. Altpeter F., Xu J. and Ahmed S. (2000). Generation of large numbers of independently transformed fertile perennial ryegrass (Loliumperenne L.) plants of forage- and turf type cultivars. Mol. Breeding 6: 519-528.

vi. American Cancer Society, (2018). 
vii. Binhi V., Ladimir N; Repiv, A. and Edelev M. translators from Russian (2002). Magnetobiology: Underlying physical problem. San Diego: Academic press.

viii. Chemes HE (2001). Infancy is not a quiescent period of testicular development. Int. J. Andrology 24: 2-7.

ix. Christ, A., Gosselin, M.C., Christopoulou, M., Kuhn, S., and Kuster, N. (2010). Age dependent tissue-specific exposure of cell phone users. Phys. Med. Biol. 55(7): 1767-1783. doi:10.1088/ 0031-9155/55/7/001.

x. Delgado J.M., Leal J., Monteagudo J.L., Garcia M.G. (may 1982) 'Embryological changes induced by weak extremely low frequency electromagnetic fields' Journal of Anatomy 13(493)533.

xi. Erogul 0, Oztas E, Yildirim I, Kir T, Aydur E, Komesli G, Irkilata HC, Irmak MK, Peker AF. (2006). Effects of electromagnetic radiation from a cellular phone on human sperm motility: an in vitro study. Arch Med Res.37(7):840-3.)

xii. Fews A P., Henshaw D.L., Wilding R. J; Keitch P A. (1999). 'Corona ions from power lines and increased exposure to pollutant aerosols'International Journal of Radiation Biology. 75(12);1523-3.

xiii. GandhiOP,Lazzi Gand Furse C1996 Electromagnetic absorption in the human head and neck for mobile telephones at $835 \mathrm{MHz}$ and $1900 \mathrm{MHz}$ IEEE Trans. Microw. Theory Tech. 44 1884-97.

xiv. Henderson and Anderson (1986) effect on the increase in cancer on both male and female living near the mast.

xv. Huss A; Spoerri A., Egger M., Swiss national cohort, study, (2009) 'Residence near power lines and mortality from neurodegenerative disease; longitudinal study of the swiss population' American Journal of Epidemiology 169(2).

xvi. IEEE (2005) Standard for safety levels with respect to human exposure to radio frequency electromagnetic fields, $3 \mathrm{kHz}$ to $300 \mathrm{GHz}$ Std C95.1 http://www.ieee.org

xvii. International commission on non-ionizing radiation protection (ICNIRP: 1998) 'Guidelines for limiting exposure to time-varying electric magnetic and EMF (up to 300GHz)' Health physics. 74(4); 494-522.

xviii. IoannisMagras and Thomas D. Xenos (1997): RF Radiation-Induced Changes in the Prenatal Development of Mice (1997), Bioelectromagnetics 18:455-461 J Wiart, A Hadjem, M F Wong and I Bloch, Analysis of RF exposure in the head tissues of children and adults, Phys. Med. Biol. 53 (2008) 3681-3695.

xix. Martoja R, Martoja M (1967) Introduction to techniques of animal histology. Eds Masson et cie, Paris pp: 343.

xx. Maslanyi M., Lightfoot T., Schuz J., Siemkiewicz. Z., Mckinlay A.(2010). 'A Precautionary public health protection strategy for the possible risk of childhood leukemia from exposure to power freq. magnetic fields' BMC public health 10:673.

xxi. Okechukwu CE (2018) Effects of mobile phone radiation and exercise on testicular function in male Wistar rats. Niger J Exp Clin Biosci;6:51-8.

xxii. Park, Robert L. (2002). 'Voodoo Science: The road from foolishness to fraud". Oxford UK and NY; Oxford University press.

xxiii. 'SAGE(2011) first interim assessment: Power lines and property, wiring in homes and electrical equipment in homes'

xxiv. Salama N, Kishimoto T, Kanayama HO (2010). Effects of exposure to a mobile phone on testicular function and structure in adult rabbit. Int J Androl; 33: 88-94.

xxv. Schinckel A, Johnson RK, Pumfrey RA, Zimmerman DR (1983) Testicular growth in boars of different genetic lines and its relationship to reproductive performance. J AnimSci 56: 1065-76.

xxvi. Sirav and Seyhan (2019), Joseph et al. (2010) on cell and broadcast tower transmissions.

xxvii. Tegegne A, Entwistle KW, Mukasamugerwa E (1991) A quantitative histological study of testicular and epididymal development in boran and boran-x Friesian bulls in Ethiopia. Theriogenology 35: 991-1000. 